\title{
IJTARP
}

\section{Formal and Informal Use of TA Counselling in Education}

\author{
(C) 2020 Piotr Jusik
}

We thank the previous publishers for permission to republish this article, which previously appeared as Jusik, P. (2017) Formal and Informal Use of TA Counselling in Education. Edukacyjna Analiza Transakcyjna, 6, 67-85. We have retained the structure and referencing of that article.

\section{Summary}

This article applies role theory and thus clarifies the differences between educators and counsellors who use transactional analysis as a method of conceptualising their work to support growth and development of learners. Educators are seen as facilitators of growth that results from acquiring knowledge, skills and understanding, whereas counsellors emphasise growth resulting from introspection based on relational experiences with the practitioner. Furthermore, counselling interventions can be differentiated into formal and informal work that show considerable differences in terms of contract, roles, levels of containment and confidentiality. Several transactional analysis models have been described in the context of formal and informal interventions. Relevant case studies have been presented to show how the concepts are applied in an educational environment. The author suggests that transactional analysis counsellors need to bring awareness into the roles that they hold and their ability to account for role differences will make their interventions more robust.

\section{Keywords}

counselling, formal and informal counselling, counselling roles.

\section{Introduction}

Transactional Analysis is a rich system of psychology that has significantly evolved since the 1960's. This process of development enabled considerable adaptability of TA that is currently applied in the fields of psychotherapy, counselling, education and organisational development. The breadth and depth of contemporary TA creates opportunities for a variety of styles to emerge and a variety of roles to be inhabited
This variety is pertinent to the counselling field that underlines the multitude of roles held by a transactional analysis counsellor. However, this diverse nature of the counselling field requires practitioners to 'differentiate roles situationally' (Schmid, 1994, p. 33) and thus consider the impact of their possible interventions with utmost care. This article will describe a number of concepts relevant to TA practitioners that work in education and hold a frame of reference of a TA counsellor.

\section{Educators and Counsellors}

The role concept is a useful construct that helps TA counselling practitioners to organise their inquiry, think about their interventions and establish clarity when an individual holds more than one role. Schmid (1994, p. 31 ) defines a role as an extension of the concept of an ego state: a coherent pattern of thinking, feeling and behaving, a perspective on reality with a set of accompanying relationships. For example, this definition can be used to differentiate between the role of an educator and a transactional analysis counsellor, both of whom may work in an educational context. The patterns of thinking, feeling and behaving will be different for these practitioners since educators are expected to hold parental responsibilities of nurturing and structuring whereas counsellors invite Adult-Adult relationships. Even though educators may work from the same humanistic stance as counsellors, they have a covert contract with society to transfer cultural heritage, values and beliefs in a sort of transgenerational transaction. Educators are there to partially provide introjective material and thus enable continuity to a society's identity. For counsellors, the main emphasis is on strengthening the Adult ego state (Tudor, Summers, 2000, p. 26) in order to enhance the clients' capacity to respond to the here-and-now. As such, education is solely a context (Napper, 2010, p. 187-188) for a counsellor, rather than a main focus that traditionally highlights imparting knowledge, skills and understanding. TA counsellors focus on strengthening the Adult by uncovering the client's internal and external resources, whereas TA educ- 
ators focus on growth resulting from learning. In the context of the education system and secondary schooling, the following metaphor can be considered: education is an equivalent to climbing up a mountain that is chosen by the educator and providing support and challenge along the way. In contrast, counselling is an equivalent to a hike, the itinerary of which is decided by both parties: it can include valleys, mountains and gorges and it serves to enhance the experience of the hiker. Table 1 shows the differences in roles between educators and counsellors in the context of formal schooling.

This role distinction gives the practitioner clarity and thus increases the potential to contain volatile situations, especially in educational environments with challenging students. It also paves the way for smoother learning, greater achievement and promotes the learner's ownership of the process. For instance, a teacher who acts in a relationally responsive way towards the students is able to hold and contain the anxieties that arise during the learning process. The practitioner is aware of his limits and if a student keeps inviting a therapeutic conversation that aims to solve a particular issue, the teacher can openly name this and suggest that the student speak to the school counsellor: "I think it is best if you speak to the school counsellor as they are the most appropriate port of call for you..."

In contrast, if a practitioner is unclear about the held role, it could lead to breaching of the contract with the institution, role confusion and games. For example, if a teacher behaves as a mother or father towards the students it would result in unhealthy levels of involvement. Another example is when a learning mentor behaves as if they were a therapeutic counsellor. This would lead the student towards disproportionate over-exposure and potentially inappropriate vulnerability. Imagine a young learner divulging their innermost secrets to a staff member who is not fully trained and works only intuitively. One can only expect an upcoming game pay off of feelings of betrayal and disappointment in the child and superiority coupled with misunderstanding on the part of the practitioner. Therefore, it is important to understand the roles that we hold and approach them with awareness, humility and courage.

\section{Formal and Informal Counselling}

Now that we have some understanding of the differences between the fields of counselling and education, we can distinguish between formal and informal counselling roles. This article introduces concepts that can be used formally and informally in the world of education by TA practitioners. However, this distinction of formal and informal use is not absolute due to the flexibility and adaptability of the concepts. Formal use is defined as ongoing and timed sessions based on a relationship and an explicit contract (Berne, 1966 p. 362). On the other hand, informal use is defined as incidental conversations that aim to promote well-being and autonomy within the education environment. Formal work takes place within a 'boundaried' environment that provides

\begin{tabular}{|c|l|l|}
\hline Role Components & \multicolumn{1}{|c|}{ TA Educators } & \multicolumn{1}{c|}{ TA Counsellors } \\
\hline $\begin{array}{c}\text { A set of thinking, feeling and } \\
\text { behaving }\end{array}$ & $\begin{array}{l}\text { Functional Adult ego state needed to } \\
\text { account for internal and external } \\
\text { reality } \\
\text { Functional Parent ego states needed } \\
\text { to structure the learning and nurture } \\
\text { the student }\end{array}$ & $\begin{array}{l}\text { Functional Adult ego state needed } \\
\text { to model accounting for the here- } \\
\text { and-now }\end{array}$ \\
\hline account for relational processes \\
(more emphasis on introspection) \\
A perspective on reality & $\begin{array}{l}\text { Imparting knowledge, skills and } \\
\text { understanding - developing } \\
\text { capacities of the Functional Adult } \\
\text { Parental responsibilities } \\
\text { Promoting growth resulting from } \\
\text { teaching and learning }\end{array}$ & $\begin{array}{l}\text { Strengthening the Structural Adult } \\
\text { ego state of the client } \\
\text { Supporting autonomy } \\
\text { Promoting growth resulting from } \\
\text { relational experiences }\end{array}$ \\
\hline A set of relationships & $\begin{array}{l}\text { Student - teacher relationship } \\
\text { Parent - Child transactions }\end{array}$ & $\begin{array}{l}\text { Mentor, coach, teacher, assistant, } \\
\text { counsellor - student } \\
\text { Adult - Adult transactions }\end{array}$ \\
\hline
\end{tabular}

Table 1: Distinction between educational and counselling roles 
opportunity for high levels of physical and emotional containment. The roles held are that of a client (who in this context is also a learner) and a counsellor (here understood as a therapist). This type of work offers higher client confidentiality that is determined by the context. For example, a university counselling service can offer a more confidential service than a secondary school where there are child protection implications. Limits of confidentiality have to be made clear to the client (learner) from the outset as otherwise it will lead to a game. Furthermore, the psychological contract in formal work focalises on a specific problem that is relevant to the learner's life at the moment. In contrast, informal work by its very nature can take place in a variety of environments and thus implies lower levels of physical and emotional containment. Confidentiality is also compromised as any incidental conversations can be interrupted by an unexpected visitor. There is a variety of roles that include the learner on one side and an educator, mentor, teacher, teaching assistant, coach on the other side to name a few. The psychological contract implies the practitioner's emotional availability that is geared to support the learner's well-being. Thus, there are differences in levels of physical containment, confidentiality, contract and roles as presented in Table 2 .

\section{Formal Counselling}

Formal counselling in an educational environment is a valuable resource because it helps the learners to solve specific issues by strengthening their structural Adult ego state. However, there is a number of considerations of the process and a sound understanding of the circumstances of formal counselling will contribute to greater awareness and hopefully better client outcomes. First of all, within an institution there is a referral process that provides guidelines for learners how to access the service. In a school environment (both primary and secondary) the pupil may be referred by teachers or form tutors if they feel concerned about the well-being of a pupil. Additionally, parental consent is required since the young client is under the custody of parents or carers. In further education institutions learners can self-refer when they recognise their need for support. In both cases there is a 3-cornered contract (English, 1975, p. 383) in place as shown visually in Figure 1.

\begin{tabular}{|c|c|c|c|c|}
\hline & Containment & Role & Confidentiality & Contract \\
\hline formal & higher & client therapist & higher & $\begin{array}{c}\text { I'm here to work with you on } \\
\text { your problem }\end{array}$ \\
\hline informal & lower & $\begin{array}{c}\text { learner educator, coach, } \\
\text { mentor, assistant, teacher }\end{array}$ & lower & $\begin{array}{c}\text { I'm here to support your } \\
\text { wellbeing } \\
\text { I'm available }\end{array}$ \\
\hline
\end{tabular}

Table 2 Distinction between formal and informal counselling roles

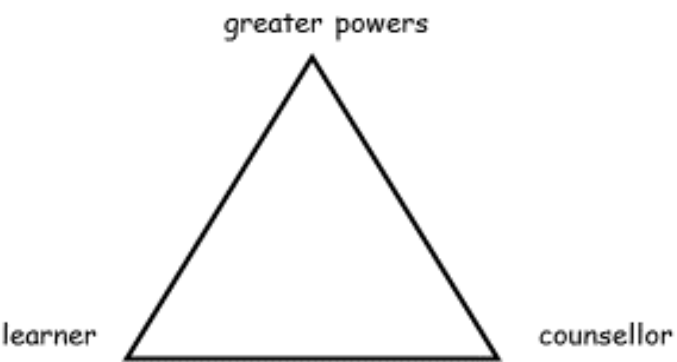

According to English (1975) when contracting with multiple parties, the following have to be considered:

-What is our contract? What did you come for?

-What is your fantasy expectation?

-How might you be disappointed by our work?

-What cannot be met.

-How can we feel empowered together even if the great power were not realistic?

Figure 1 Contracting considerations with multiple parties. 
For a counsellor working in an institutional context, it is important to account for psychological distance (Micholt, 1992, p. 229) and the different agendas of the parties involved. Ideally, all parties should be in an equal balance, meaning that no one should have a dominant position or exclude one of the parties. Thus, the multiple agendas need to be named in order for everyone's position to be valued and accounted for. For instance, a student counselling service at a university is expected by the management to contribute to student retention and enable the student population to be sufficiently well in order to graduate. A student might pick up on that, and experience the support as conditional. A skilled counsellor is able to name the multiple contracts with clarity and hold in mind the student's perspective. It will help the practitioner to be aware of game invitations ("The University only wants my money, that's why they offered me counselling...") and promote a realistic appraisal of reality. Having said that, counsellors are frequently seen in systems as 'fixers'. Sometimes students get referred to a school counsellor as some aspect of their behaviour is seen as problematic to other staff members or pupils. Thus, a fantasy expectation is placed on the counsellor who is there to 'fix' the student. This needs to be understood and accounted for as otherwise the learner/client might use it to confirm some of their script beliefs, for example 'I am not worthy of help'. Therefore, a skilled counsellor would be aware of the external forces that shape the process of counselling (before it even starts!) and proceed with caution.

Contracting is key in transactional analysis. Steiner (1969, p. 29-31) describes conditions conducive for good contracting and this enables troubleshooting at the initial stages of work. According to Steiner, sound contracting is based on a number of factors outlined below.

- Mutual agreement - both parties agree voluntarily to enter the process. This is quite obvious in a university or other higher education institution; however in a secondary school many parties are involved (parents, teachers, tutors, other professionals and the student) who need to be on the same page. Furthermore, there are some child clients who agree at the overt level, but do not acknowledge the value of counselling at the covert level. They might do it to adapt, to please their parents and teachers rather than understand themselves. Thus, it is important to enquire about the ' $W H Y$ ' of the counselling. At the same time, if a child is anxious or depressed, it is the parents' or carers' role to ensure that the young person attends the session. A child may not be in a position to 'agree' and as such parents can decide from a structuring stance as to what is useful, beneficial or required for a healthy development of their child.

- Valid consideration - there is some financial or other forms of acknowledgement of the exchange of skills, time and effort of the counsellor for the benefits received by the client. In an institutional context, this is simply the salary that the practitioner receives. However, it is interesting that when students do not directly pay the counsellor, they tend to perceive the service as free. Rarely do they see their university fees as a direct payment for the sessions attended. According to the author's experience, students tend to see the counsellor as a part of a system and may bring their transferences to the consulting room, recreating a microcosm of the institution through the quality of their relationship with the practitioner. Sometimes, it may lead the client to cancel their session or skip some of them altogether. It is worth enquiring of a client in an institutional context, their perceived value of the sessions and how it impacts their commitment to the process.

- Competency - the client needs to access the service with sufficient awareness and understanding of the process in order for his efforts to be viable. Thus, clients who are under the influence of alcohol or drugs are not competent to enter the counselling process. In TA terms, this means having sufficient availability of the Adult ego state in order for clients to be available to their own experiences. This way they are able to engage and find their own resources. On the other hand, it may be the case that a young learner has severe needs that cannot be met within the institutional context and has to be referred elsewhere.

- Lawful object - the practice of counselling has to follow the law of the land, meaning it has to be consistent with the rules and regulations of the specific context. In a schooling environment there are child protection implications and should there be a need, the relevant personnel needs to be informed about any issues related to physical or psychological abuse, neglect, bullying, grooming and any other potential risk factor to the wellbeing of the pupil.

These four conditions help to consider the beginning of counselling and provide a clear point of reference that paves the way for success.

Counsellors working in an educational environment often have to provide brief therapy which requires a finely tuned set of skills. Grant (2013, p. 61-66) presents an elegant outline of short-term counselling 
from a transactional analysis point of view. According to Grant, the five essential ingredients in short-term counselling include:

1. Holding the possibility of one session cure. In a nutshell, the clients' well-being is the most important. Lengthy and laborious analyses are seen as "Making progress" (Berne, 1972, p. 377). The counsellor enters each session with a curious and fresh mind that acts like fertile ground for the change to happen today. Not tomorrow, not in six months, but today!

\section{Establishing a relationship.}

It is widely known that $30 \%$ of therapeutic change can be attributed to relational factors (Lambert, Barley, 2002, p. 357-361). Even though the therapy is brief (for example 6 sessions), it is important to allow the client to feel relationally significant. The client needs to feel that he is held in mind and thus learns to create a holding and relationally attuned and responsive internal environment. (Epstein, 2014, p. 38) Otherwise, the impact of counselling will only be short lived and rather insignificant.

\section{Contracting.}

Views on contracting have been already described, however the phrase "mutual agreement" still leaves room for interpretation. The counsellor needs to be realistic in terms of the contract offered to the client. According to Berne (1961, p. 160), there are four goals of therapy:
1) symptomatic control,
2) symptomatic relief,
3) transference cure,
4) psychoanalytic cure.

Grant suggests that short-term therapy is likely to address goals 1) and 2) since they require less time in comparison to 3) and 4) which rely heavily on the development of a strong and established long term relationship with the therapist. It is crucial to be clear when contracting and be realistic about the outcome that can be achieved.

4. Being a keen observer.

The devil is in the detail and this is the case in counselling as well. Sound observation coupled with honed intuition are key to accurate assessment and planning of the process. Berne recommends using all senses in order to pick up any relevant detail. This approach enables the practitioner to become aware of the multiple levels of the process which leads to refinement of the counselling practice.

\section{Leverage.}

The last ingredient underlines the value of good assessment and good interventions. An effective counsellor has to dynamically assess the situation and respond to the client in ways that will consistently invite autonomy.

\section{An Example}

These principles can be illustrated using a case example: Tom was a 22 year old male who selfreferred to the university counselling service with depression and anxiety. He had a strong need to be 'diagnosed' and was quite determined to find the root cause of his current state of mind. He was inviting me to find fault in him through some phrases along the lines of "What is wrong with me?" or "Can you tell me what the problem with me is?" At this stage, I was still and kind, allowing him to define his relational space in the consulting room. I was also clear that we could only explore a fraction of his issues, as the university offers short term counselling, which is part of the university system support mechanisms. Our contracting was sound and Tom accepted that the service offered could only be a starting point in his quest for wellbeing.

I insisted on seeing each session as impactful through creating an ambiance of urgency: "In 10 minutes you will leave this room and come back to your life... What would you like to be different? What parts of you need urgent care at the moment that you cannot afford to ignore?" Tom responded well and engaged in the processes by coming back with session to session contracts. We would practice mindfulness skills together or use various objects to represent his inner world. Most of all, I was open, available and relationally responsive in a gentle and kind manner. I also categorically refused to 'fix' him which was his script belief that I did not want to confirm in any shape or form. In fact, I was more concerned with his strengths, resources and the options that he could create in his life. This was somewhat liberating for him, as he no longer felt the need to improve himself. Figure 2 shows my assessment of the client in terms of drivers, injunctions, discounting and rackets. I identified the relational needs (Erskine, 1996, p. 322) that were crucial to establishing a contactful and responsive relationship. Tom finished his counselling after 8 sessions and wrote me a note (Figure 3) that summarises his perception of the process. This case study exemplifies the principles of transactional analysis counselling from a formal perspective and demonstrates that TA is an effective tool for growth and change.

\section{Informal Counselling}

Informal counselling relies on the deliberate use of TA concepts in places other than the consulting room. It gives the practitioner many options to have a positive impact on the learner, even though the interactions might be brief. However, it is the quality of relationship and the interpersonal dynamics that determine the success of interventions. 


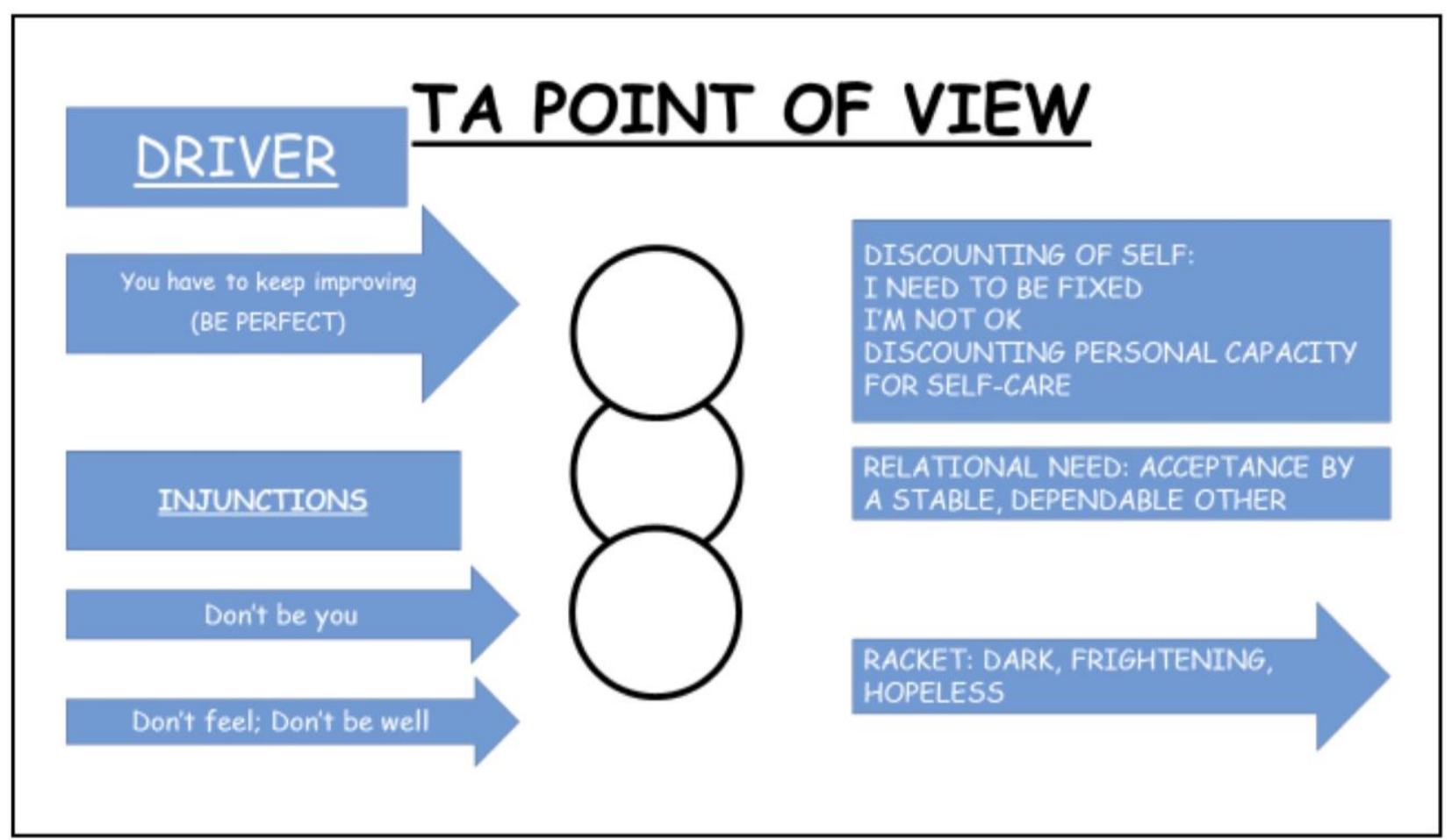

Figure 2: Assessment of a client in terms of injunctions, drivers, discounts and rackets

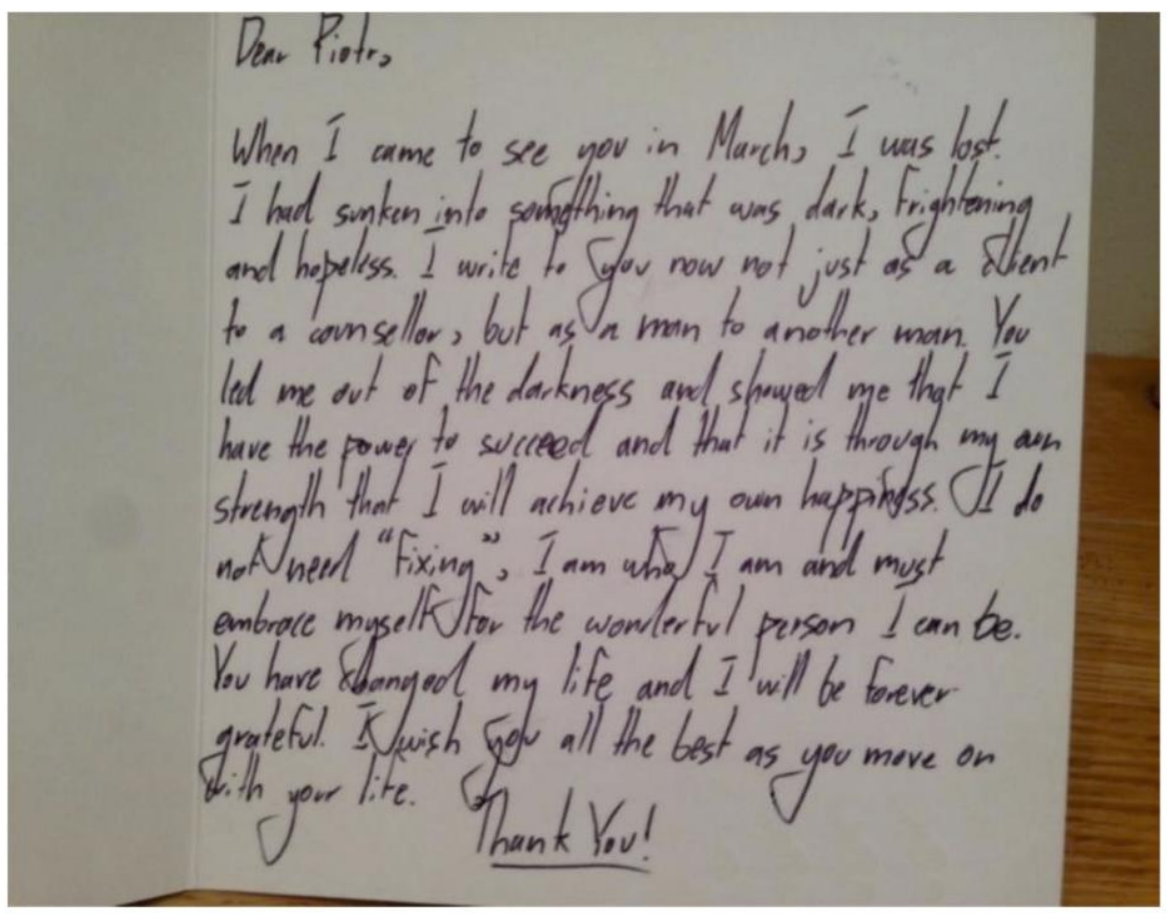

Figure 3: Student (client) note showing their perception of the counselling process 
In terms of a schooling environment, one of the most inefficient ways of human contact are psychological games. Usually, pupils would initiate gamy interactions when they feel overwhelmed and unable to contain their anxiety that accompanies their learning. Games start with a discount and it seems a good moment to intervene in order to promote classroom behaviour based on autonomy. Barrow (2011, p. 4) outlines the role of an educator in relation to different levels of discounting present in the learner's frame of reference.

Table 3 summarises concisely what is required at each level. I will illustrate this concept using a case study.

\begin{tabular}{|c|c|}
\hline Level of Discount & Role of a practitioner \\
\hline Existence & Recognise \\
\hline Significance & Reassure \\
\hline Solvability (options) & Reconnoitre \\
\hline Personal capacity & Reflect \\
\hline
\end{tabular}

Table 3: Role of a practitioner in relation to levels of discounting Adapted from Barrow, 2011, p. 4.

Kate was a challenging 14 year student who was excluded from mainstream education. She was quite confident and knew how to defend herself in tough situations that arose in the pupil referral unit where I taught Science. Despite her levels of self-assurance, she was somewhat doubtful of her ability nd did not want to engage in learning. Initially, she spent most of her lessons outside the school engaging in banter, smoking and essentially avoiding my classroom as much as possible. In TA terms, she was discounting the existence of the lesson and discounting her existence as a learner. I needed to recognise Kate's lack of engagement and recognise her as someone who was potentially capable of learning. As months passed, she would gradually appear in class and was willing to learn. My role was to reassure her and provide her with appropriate strokes. I realised that I was significant to her when she appeared very displeased after my three day absence due to an illness. She greeted me with words, "Hello stranger!", indicating that it was rather outrageous of me to be out of work for three days. At this point we built enough trust and Kate grew increasingly in independence. She was willing to complete her exam lab assignments and my role was to explore (reconnoitre) the best options of answering exam questions. We were on a quest of seeking good exam preparation skills. As our teacher - student relationship was drawing to an end, Kate became increasingly reflective... not only about her learning but about life. She was able to recognise a colleague of mine (who was in her sixties) as someone who held the psychological leadership within the school ("Barbara is a bit like a grandmother in this school, isn't she...?"). On her last day, Kate gave me a card written in Google translated Polish that clearly showed the journey she has been on. She indicated that initially she did not like me. My role was to hold this negative transference when Kate moved from recognising the existence of her ability to learn into understanding the significance of the end of her secondary education. At this point, her emerging sense of self as a learner needed protection and reassurance. This is evident from the card she wrote to me as shown in Figure 4. This example shows the development of a learner's awareness development and how the need to invite games though discounts is gradually replaced by Adult accounting.

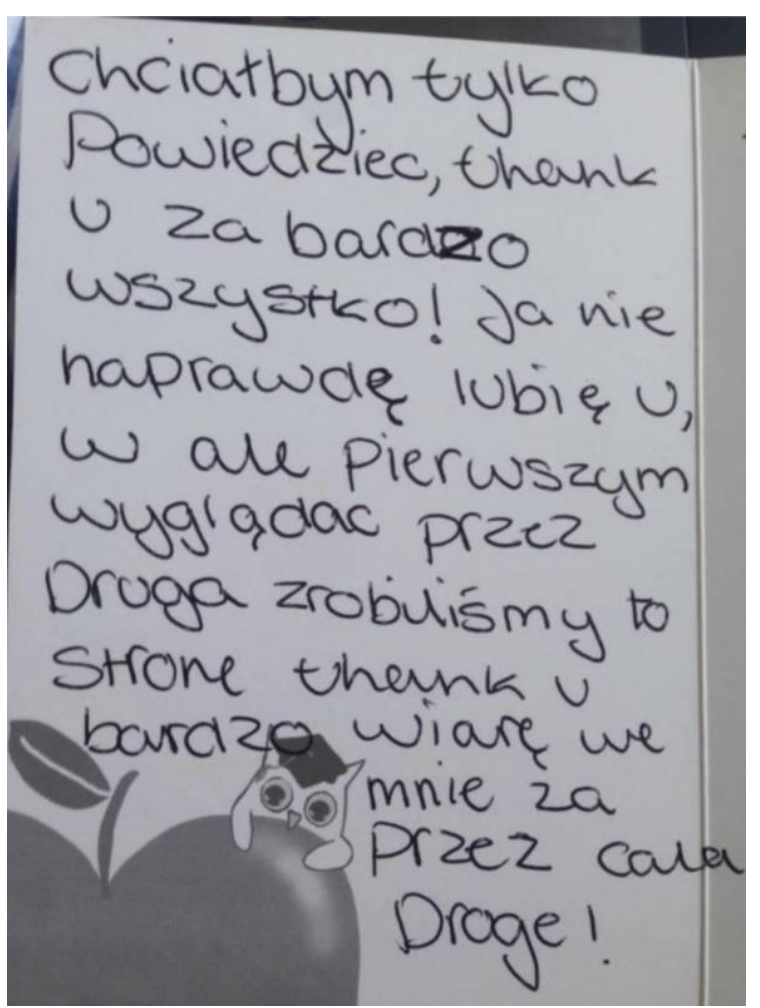

Figure 4: Student note showing their perception of personal change

There are, regrettably, cases in which the theory just simply does not help because the complexity of human nature does not respond to solutions that solely address one cause. In one of my teaching positions, I came across a fifteen year old defiant male student who had some traits of ADHD. He was very much unwilling to fit into the institutional culture and kept inviting conflicting responses from staff members. At some point, he decided to complain about my conduct to the school principal. The student claimed that I was too demanding. As a result, a small investigation was launched aiming to find any possible sources of my incompetence. Several months following the incidents, the student proclaimed during a lesson in front of all pupils: 'Mr Piotr, do you remember when I tried to have you lose your job'. He clearly admitted that the only motive for his behaviour was to get rid of me since I 
challenged his behaviour. Despite my efforts to recognise his learning potential, it just did not work and the student ended up being excluded from school. He was too locked in his script position and would not allow others to have an impact on his frame of reference. Another example of non-responsiveness is when some students can become over-reliant on the support they receive and develop learned helplessness. They expect that every assignment will be provided with a scaffold or other materials that enable the completion of the task. Even though many teachers reassure the students of their capacity to work independently, the pupils become overly dependent on reassurance they receive. They end up creating a world view that assumes that there will always be a parental figure, ready and willing to provide them with containment. However, the student's role is also to be able to tolerate some temporary discomfort and develop their inner resources as a result of learning. The reflection that leads to developing inner resources may not always be possible for every student; for example, some pupils on the autistic spectrum disorder may fixate on particular points of view. It seems that they are impenetrable and their self-beliefs ("I'm rubbish!") cannot undergo scrutiny as they might not be able to develop a high degree of understanding of social situations. Therefore, there are also limits to what transactional analysis as a humanistic psychology can offer.

\section{Relational Modalities}

The last section will outline Clarkson's (2014, p. 6-22) model of relationship modalities translated into classroom practice from a point of view of informal counselling interventions. Each relationship modality requires the practitioner to take into account the nature of the relational processes at hand.

The first type of relationship modality pertinent to an educational environment is a working alliance. Clarkson (2014, p. 6-22) suggest that this involves establishing some basic cooperation that is imbued with warmth, trust and kindness. This was apparent in my classroom practice through the atmosphere that a student would step into. Figure 5 shows my classroom that would explicitly greet the student with a message: "Learning to be together". Thus, the aim was to provide the pupils with strokes in order to create an optimal learning environment as well as to provide ground rules through clear contracts in order to manage expectations. As a result, the learner steps into a mixture of nurture and structure that allows them to understand the parameters of what is acceptable and expected within the classroom. It also gives students a sense of belonging and safety.

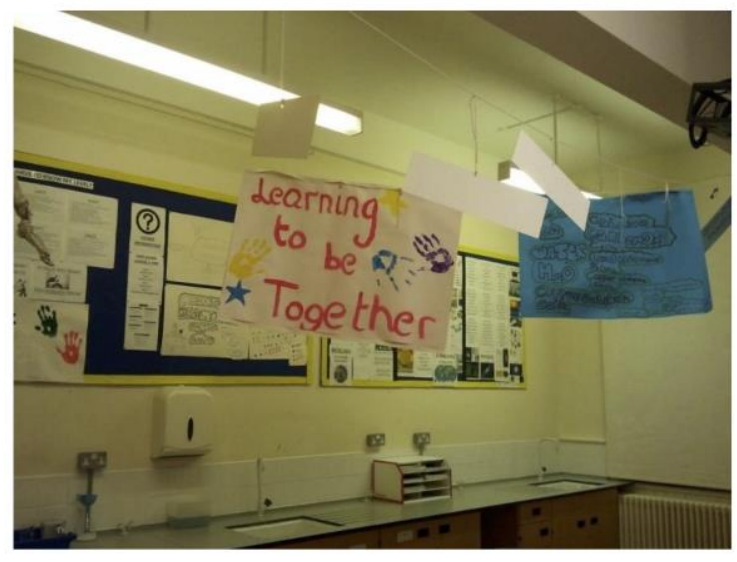

Figure 5: Classroom view that greets the learner

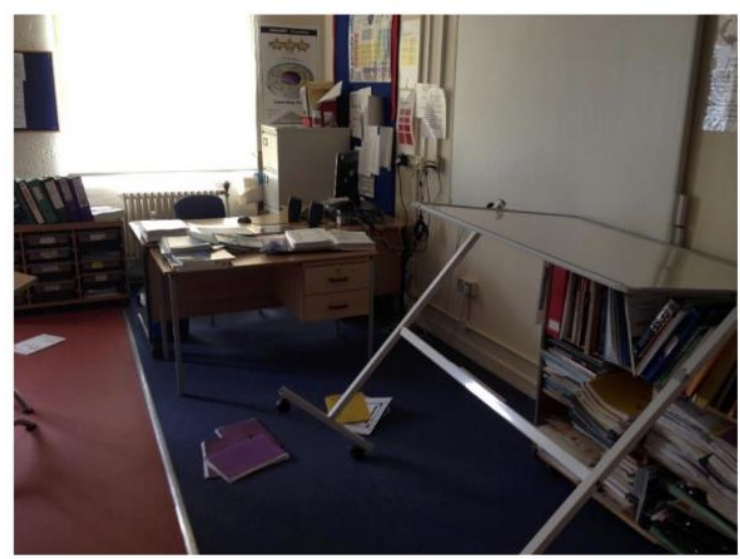

Figure 6: Vandalised classroom.

However, as with every relationship development, there is scope for transference phenomena to arise leading to a transferential relationship. On some occasions, my classroom would be simply trashed and vandalised (Figure 6) since I would represent some negative aspects of students' past experiences at school. They would possibly see me as a critical figure that would seek to invalidate their point of view and write them off as incapable of thinking and learning.

When the pupils came in trying to damage the equipment in my room, my role was to act with integrity and in ways that were consistent with my professional values. Thus, I had to name the behaviours as unacceptable and at the same time make the point that I was very different to their transferential expectations, which portrayed me to be condescending and punitive. My values such as curiosity and growth manifested through my preparedness to meet the students wherever they were at, to listen and pay attention to what was healthy in their behaviour. For example, if a student took interest in some completely random part 
of Science, I would follow their experience by cocreating the lesson, rather than worrying about the curriculum. It was a balancing act - one of my managers compared it to surfing when one tries to ride a rough wave rather than taming it; it is about feeling it and following the flow.

Some of my teacher-student relationships would stay stuck at the transferential stage, however there were pupils ready and willing to enter a developmentally needed relationship. Once they tested me enough and concluded that the relationship was safe, my role was to identify the students' specific learning and emotional needs. As this would fall into informal interventions, I would not share my explicit thinking with the student as would be the case in the therapy room. I offered learning options that would meet the students' needs by providing appropriate and relevant structure, nurture and challenge. The contractual aspect concerned my emotional availability to what emerged in the context of learning. In my role, I did not specify the students' issues or invite a therapeutic conversation. The interventions were present through the provision of a relationally and developmentally attuned environment. For example, some pupils did not have enough play throughout their childhood and they needed to use more of their Child ego state (Little Professor - A1 in this case) to mess around before their Adult (A2) was prepared to learn. In simple words, we would just engage in play until they were ready to learn. It also required me to be clear about the limits of play... and when they could not stand the boundaries, they would go back to a transferential relationship, rebel and throw their 'toys' out of the pram. Again, my role was to hold the boundaries and model a holding relationship since often the students were not held and contained by consistent expectations. This was a part of providing a developmentally needed experience through ground rules. Figure 7 shows how a student explored the idea of a centre of gravity during a Science lesson. This was a starting point of a learning process where the student could test his intuitive ideas, play around and improve his reality testing abilities. To conclude, a developmentally needed relationship paves the way for solid student growth through a provision of replenishing experiences that meet them where they are at.

The person-to-person relationship develops when both the student and teacher are ready to see each other without the need to resort to games. This type of relationship is also called the real relationship and is considered in the counselling world as the healing aspect of human connection. It is when both the student and the teacher mutually recognise their human struggle with deep regard. I have witnessed this relationship modality when a student and myself would simply respect each other and express that through silent understanding and a non-possessive exchange of strokes. One female student left me a note (Figure 8 ) on the board of my classroom... and brought me a Mojito making drink set as a sign of gratitude. I recognised her hardship through my playful attitude in the lessons and moments of silent work that would validate the student as a thinker. On the other hand, she understood the difficulty of my role. It is a hard job to teach students that are emotionally challenging... and it does make one want to have a mojito on a Friday night to 'take the edge off'. The student's gift was also an acknowledgement that life can be overwhelming for many and an invitation to see ourselves as fallible and yet showing understanding for our hardships. This type of relationship requires the most skills and it is important to enter it with openness and awareness. It is not to serve the practitioner as a source of recognition but it is a relationship built on integrity and good faith that potentially is transformative for the student.

Last but not least, on very rare occasions, it is possible to witness some traces of a transpersonal relationship within the classroom. It is a sense of connection that has some timeless quality and when expectations are dropped and when some universal, perhaps divine, qualities emerge. For example, a student in my colleague's English classroom looked very reflectively through the window on a rainy and dark late November afternoon. All of a sudden, the ambiance became very still and the pupil asked the teacher: "Miss, why is it that everybody dies but not everybody lives...?" The teacher did not answer the question but held the

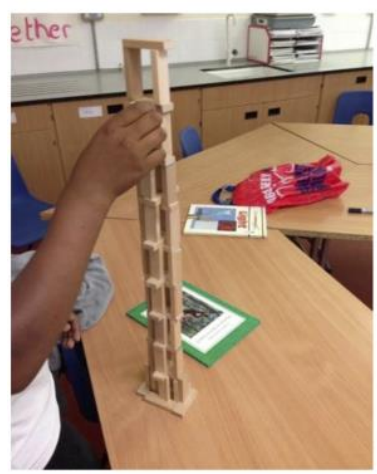

Figure 7 Engaging students through play.

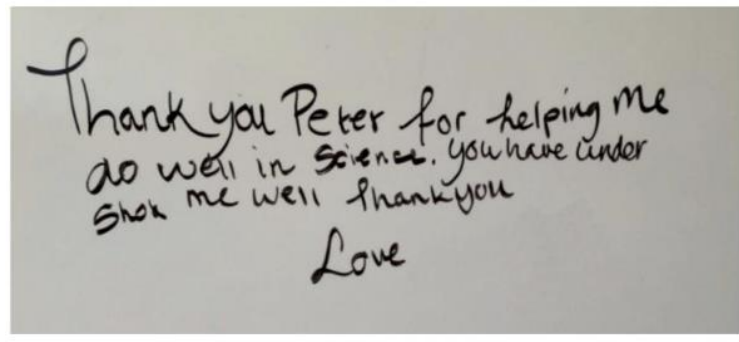

Figure 8: Student note showing connection 


\begin{tabular}{|c|c|}
\hline Working alliance & $\begin{array}{l}\text { - } \quad \text { Provide strokes to create an optimal learning environment } \\
\text { - } \quad \text { Offer clear contracts to manage expectations }\end{array}$ \\
\hline Transferential relationship & $\begin{array}{l}\text { - Act with integrity based on the practitioner's professional } \\
\text { values } \\
\text { Make a point to be different than the transferential } \\
\text { expectation }\end{array}$ \\
\hline Developmentally needed relationship & $\begin{array}{l}\text { - } \quad \text { Identify specific learning and emotional needs } \\
\text { Provide appropriate and relevant nurture, structure and } \\
\text { challenge }\end{array}$ \\
\hline Person-to-person relationship & $\begin{array}{l}\text { - Mutually recognise humanity and human struggle in each } \\
\text { other } \\
\text { - Enjoy an appropriate and non-possessive exchange of } \\
\text { strokes }\end{array}$ \\
\hline Transpersonal relationship & $\begin{array}{l}\text { - } \quad \text { Allow yourself to be impacted by the unknown and elusive } \\
\text { - } \quad \text { Allow meaning to emerge from co-creation }\end{array}$ \\
\hline
\end{tabular}

Table 4: Role of a practitioner in relation to different relationship modalities. Adapted from Clarkson, (2014), p. 622.

silence. My colleague's intention was to create a permissive space where profound questions could be asked without the interference of existential fear. In that moment, some timeless and universal aspect emerged which indicated that mysteries of existence cannot be understood per se, but felt perhaps... Thus, the transpersonal relationship cannot be forced or programmed for. It happens sometimes and gives us some sense of wonder at the unknown and elusive. The practitioner needs to allow themselves to be impacted by the co-created meaning and develop their eldership. This is the intangible and yet so important aspect of education in which one feels that it makes sense to get up each morning and appear in the classroom whatever the circumstances, be it politics or bureaucracy... Therefore, it is important to keep our eyes and ears open as one never knows when this sort of relationship might emerge. Table 4 summarises the role of a practitioner in Clarkson's model of relationship modalities.

\section{Conclusion}

This article presented a number of transactional analysis concepts that are useful for counsellors when working both formally and informally in an educational environment. There are differences in terms of roles between educators and counsellors. There are also differences in approaches between formal and informal counselling interventions. At its humanistic core, transactional analysis can help us become closer and more authentic or... understand why we choose to play games that prevent growth and learning. In order to be fully engaged we need to draw on the resources coming from all of our ego states. This promotes resilience, achievement and a hopeful outlook on life. At the same time, many counselling practitioners who work in education may hold more than one role. They need to consider the nature of a particular role and inhabit it appropriately and with awareness. Berne (1964, p. 158) points out that awareness is one of the components of autonomy. Practitioners need to model autonomy through cultivating their self-awareness of the various elements of their roles. Consequently, they can increase their role competence (Schmid, 1994, p. 34) and become more robust. Thus, counselling in education is a quest for resources that is not for the faint-hearted.

Piotr Jusik is in training as a Certified Transactional Analyst (Counselling) and has held various roles in international education. He can be contacted on peter@iflowcoaching.com

\section{Bibliography}

Barrow, G. (2011). Educator as Cultivator. Transactional

Analysis Journal, 41 (4), 308-314.

https://doi.org/10.1177/036215371104100407.

Berne, E. (1961). Transactional analysis in psychotherapy: A systematic individual and social psychiatry. Toronto, 
Canada: Ballantine Books. https://doi.org/10.1037/11495$\underline{000}$

Berne, E. (1963). The Structure and Dynamics of Organizations and Groups. New York: Grove Press.

Berne, E. (1964). Games people play: The psychology of human relationships. New York: Grove Press.

Berne, E. (1966). Principles of group treatment. New York: Oxford University Press.

Berne, E. (1972). What do you say after you say hello?: The psychology of human destiny. Beverly Hills, CA: Corgi.

Clarkson, P. (2014). The therapeutic relationship. London: Whurr.

English, F. (1975). The Three-Cornered Contract. Transactional Analysis Journal, 5, 383-384. https://doi.org/10.1177/036215377500500413.

Epstein, M. (2014). The trauma of everyday life. Carlsbad, CA: Hay House.

Erskine, R. (2013). Life Scripts: A Transactional Analysis of Unconscious Relational Patterns. In: Napper R., The individual in context: How do I fit in around here? (p. 179201). London, England: Karnac.

Erskine, R.G.\& Trautmann, R.L. (1996). Methods of an Integrative Psychotherapy. Transactional Analysis Journal, 26 (4), 316-328.

https://doi.org/10.1177/036215379602600410

Grant, J. (2013). Short-Term Counseling and Transactional Analysis. Transactional Analysis Journal, 43 (1), 58-67. https://doi.org/10.1177/ 0362153713486110 .
Lambert, M.J., Barley, D.E. (2002). Research summary on the therapeutic relationship and psychotherapy outcome. Oxford, England: Oxford University Press.

Mellor, K., Schiff, E. (1975). Discounting. Transactional

Analysis Bulletin, 5 (3), 295-302.

https://doi.org/10.1177/036215377500500321

Micholt, N. (1992). Psychological Distance and Group Interventions. Transactional Analysis Journal, 22 (4), 228233. https://doi.org/10.1177/036215379202200406.

Schmid, B. (1994). Transactional analysis and social roles. In: G. Mohr \& T. Steinert (Eds.), Growth and change for organizations: Transactional analysis new developments 1995-2006 (p. 32-61). Pleasanton, CA: International Transactional Analysis Association.

Schmid, B. (2008). The Role Concept of Transactional Analysis and other Approaches to Personality, Encounter, and Cocreativity for All Professional Fields. Transactional Analysis Journal, 38 (1), 17-30. https://doi.org/0.1177/036215370803800104.

Steiner, C.M. \& Cassidy, W. (1969). Therapeutic contracts in group treatment. Transactional Analysis Bulletin, 8 (30), 29-31.

Summers, G. \& Tudor, K. (2000). Co-creative. Transactional Analysis. Transactional Analysis Journal, 30 (1), 23-40. https://doi.org/10.1177/036215370003000104 